\title{
Prosthetic abutment influences bone biomechanical behavior of immediately loaded implants
}

\section{Germana de Villa CAMARGOS(a) Bruno Salles SOTTO-MAIOR ${ }^{(b)}$ Wander José da SILVA(a) Priscilla Cardoso LAZARI(a) Altair Antoninha DEL BEL CURY(a)}

(a) Universidade de Campinas - UNICAMP, Piracicaba Dental School, Department of Prosthodontics and Periodontology, Piracicaba, SP, Brazil.

(b) Universidade de Juiz de Fora - UFJF, Dental School, Department of Restorative Dentistry, Juiz de Fora, MG, Brazil.
Declaration of Interests: The authors certify that they have no commercial or associative interest that represents a conflict of interest in connection with the manuscript.

Corresponding Author: Altair Antoninha Del Bel Cury E-mail: altair@unicamp.br

DOI: 10.1590/1807-3107BOR-2016.vol30.0065

Submitted: Sep 25, 2015

Accepted for publication: Feb 23, 2016

Last revision: Mar 24, 2016

\begin{abstract}
This study aimed to evaluate the influence of the type of prosthetic abutment associated to different implant connection on bone biomechanical behavior of immediately and delayed loaded implants. Computed tomography-based finite element models comprising a mandible with a single molar implant were created with different types of prosthetic abutment (UCLA or conical), implant connection (external hexagon, EH or internal hexagon, $\mathrm{IH}$ ), and occlusal loading (axial or oblique), for both immediately and delayed loaded implants. Analysis of variance at $95 \% \mathrm{CI}$ was used to evaluate the peak maximum principal stress and strain in bone after applying a $100 \mathrm{~N}$ occlusal load. The results showed that the type of prosthetic abutment influences bone stress/strain in only immediately loaded implants. Attachment of conical abutments to IH implants exhibited the best biomechanical behavior, with optimal distribution and dissipation of the load in peri-implant bone.
\end{abstract}

Keywords: Dental Implant-Abutment Design; Finite Element Analysis.

\section{Introduction}

The rehabilitation of totally or partially edentulous patients with implants is the first option to restore masticatory function and aesthetics. ${ }^{1}$ Over $90 \%$ of patients who receive implants are partially edentulous, with the single-tooth replacement being the most frequent indication. ${ }^{2}$ Nevertheless, this treatment presents a higher biomechanical challenge and has a lower success rate when compared to implant-supported partial or total fixed prostheses. ${ }^{3}$

The increased biomechanical risk of single-tooth implants has been associated with a higher magnitude of occlusal forces on these implants compared to splinted implants, ${ }^{4}$ especially when they are installed at molar sites. Occlusal overload on implants can increase the stress/strain transferred to the supporting bone, which in turn damages the physiological equilibrium of bone remodeling. ${ }^{5}$ As a result, progressive peri-implant bone resorption or osseointegration failure may occur in delayed or immediately loaded implants, respectively. ${ }^{6}$

In an effort to minimize the deleterious effects of occlusal overload on peri-implant bone tissue, some studies have showed that the geometric features of implants and their prosthetic components, such as implant connection, ${ }^{7}$ implant thread configuration, ${ }^{8}$ implant 
diameter and length, ${ }^{9}$ and prosthetic abutment angulation, ${ }^{10}$ play a significant role in occlusal load transfer to the bone-implant interface, thereby influencing the magnitude and distribution of stresses and strains in peri-implant bone. In this context, the configuration of prosthetic abutment might also affect the biomechanical behavior of implant-supported single crowns. This becomes more relevant in screw-retained prostheses, which do not have the contribution of a cement layer to help in stress dissipation and distribution. ${ }^{11}$ In these prostheses, two types of restorations can be used with respect to the abutment type: prostheses screwed directly on the implant (UCLA abutment) or prostheses with an intermediary component between the implant and prosthetic crown (Conical abutment). The latter comprises two screwed joints: one at implant-abutment interface and another at abutment-prosthesis interface. ${ }^{12}$ However, the effect of prosthetic abutment type, for single-screwed prostheses, on bone stress/strain is not yet known.

Another factor that can influence peri-implant bone stress/strain is the type of implant connection by which the prosthetic abutment is attached. Implants with external hexagon $(\mathrm{EH})$ connections have been associated with higher stress in peri-implant bone, because only the abutment screw is responsible for maintaining the stability of the connection at implant-abutment interface..$^{13}$ In contrast, implants with internal hexagon $(\mathrm{IH})$ connections present a more stable connection, which permits an even stress distribution throughout the body of the implant. ${ }^{13}$ Despite intensive study of biomechanics in the field of implantology, the relationship among biomechanics, prosthetic abutment type, and implant connection has not yet been explored. Therefore, with the use of nonlinear three-dimensional (3D) finite element analysis (FEA), this study aimed to evaluate the effects of the type of prosthetic abutment used in single-screwed prostheses and of different implant connections on bone biomechanical behavior of immediately and delayed loaded implants.

\section{Methodology}

\section{Study design}

A set of 3D virtual models were created using computer-aided design (CAD) software. Each model consisted of a single-screwed crown supported by one implant $(5.0 \times 11.5 \mathrm{~mm})$ at the first molar position of a partially edentulous mandible. The type of prosthetic abutment (UCLA or conical), implant connection (external or internal hexagon), and occlusal loading (axial or oblique) was varied for either immediately or delayed loaded implants (Figure 1). The levels of peak maximum principal stress and strain for the cortical and trabecular bone were analyzed after applying a $100 \mathrm{~N}$ occlusal load.

\section{Model construction}

The 3D virtual models of the posterior segment of a partially edentulous mandible and a single prosthetic crown were constructed based on cone
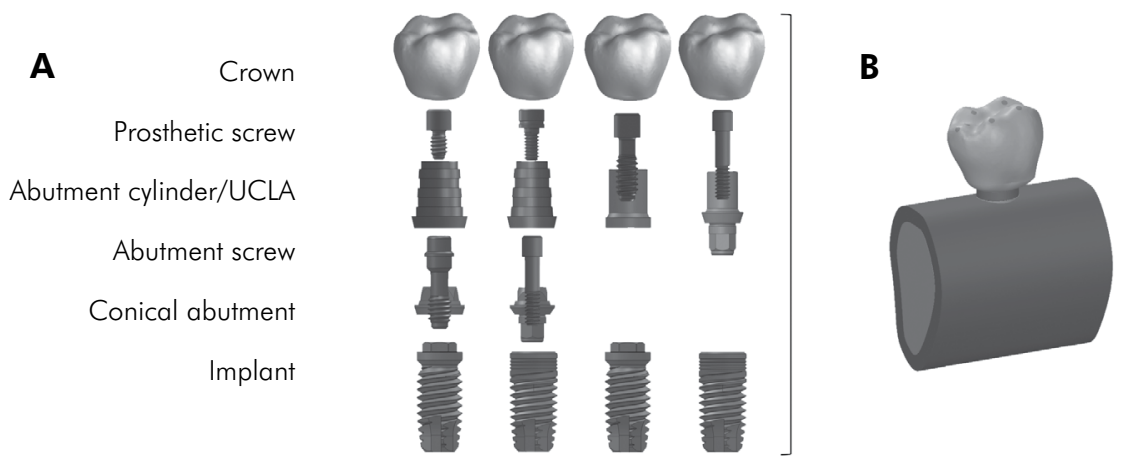

$\mathrm{EH} \quad \mathrm{H} \quad \mathrm{EH} \quad \mathrm{H}$

Figure 1.3D modeled geometries. (A) Assembly parts of all groups. (B) Example of complete assembly consisting of a single-screwed crown supported by one implant at the first molar position of a partially edentulous mandible. 
beam computed tomography (CBCT) images. The scan was performed with the Kodak 9000 3D Extraoral Imaging System (Carestream Dental LLC, Atlanta, USA), using a tube voltage of $60 \mathrm{kV}$, tube current of $2 \mathrm{~mA}$, and slice thickness of $75 \mu \mathrm{m}$. The resulting CBCT images of the mandible and first lower molar tooth were saved as.dicom files and imported into InVesalius software (ver. 3.0, 64-bit; Renato Archer Information and Technology Center, Campinas, Brazil) in order to generate 3D reconstructed models in solid-display stereolithographic file format (.stl). The 3D reconstructed images in.stl format were exported to SolidWorks 2011 software (SolidWorks Corp., Concord, USA), and, by using its Scan-to-CAD plugin function, these images were converted into 3D solid models of the posterior mandible $(14.4 \mathrm{~mm}$ buccolingual width $\times 21.0 \mathrm{~mm}$ inferosuperior height) and of the prosthetic crown $(2 \mathrm{~mm}$ occlusal thickness $\times 10 \mathrm{~mm}$ height $\times 11.5 \mathrm{~mm}$ mesiodistal width). Thereafter, these models were edited in SolidWorks, and the resulting bone model was composed of trabecular bone surrounded by $2 \mathrm{~mm}$ of cortical bone, corresponding to type II bone quality. ${ }^{14}$ Eight loading areas were also created on the occlusal surface of the prosthetic crown 3D model via Boolean operations. These loading areas simulated the occlusal contacts in molars, the number of which can vary from 1 to 10 according to Hattori et al. ${ }^{15}$

CAD solid models of implants with an EH (TitamaxTi cortical) or IH (Titamax II Plus) connection, UCLA or conical abutments, and their respective fixation screws were provided by the manufacturer (all from Neodent, Curitiba, Brazil). The implant model was positioned at the crestal bone level in a central position, and the implant insertion hole in the bone model was created by
Boolean subtraction, simulating a virtual osteotomy. Afterwards, the implant was added to the bone model, and the abutment, fixation screws, and the prosthetic crown model were then aligned and connected to the implant following the instructions from the implant manufacturer.

\section{Numeric analysis}

Material properties and mesh generation

The CAD models were imported into numerical analysis software (ANSYS Workbench 13.0; Swanson Analysis Inc., Houston, USA). The mesh was then generated ( $0.7 \mathrm{~mm}$ tetrahedral elements) and submitted to convergence analysis prior to mechanical simulation. The convergence criterion was set to be less than $6 \%$ change in highest bone stress between the models with different numbers of elements. ${ }^{16}$ As a result, the models exhibited numbers of elements ranging from 73,508 to 81,542 and numbers of nodes ranging from 125,881 to 140,179 . All structures were considered homogeneous, isotropic, and linearly elastic. The mechanical properties of all materials used are described in Table 1.

\section{Contact conditions}

The immediate loading of implants was simulated by using nonlinear frictional contact elements with a friction coefficient $(\mu)$ of 0.3 between the bone and implant. In the delayed loading situation, simulating osseointegrated implants, the bone-implant contact was assumed to be a bonded contact. The contact condition between the abutment and implant was set at a $\mu$ of 0.3 for all the simulations. ${ }^{17}$ Frictional contact configurations allow minor displacements between all components of the model without interpenetration. ${ }^{18}$

Table 1. Mechanical properties of materials used in the models.

\begin{tabular}{lcc}
\hline Material & Young modulus (MPa) & Poisson ratio \\
\hline Cortical bone & 13,700 & 0.30 \\
Trabecular bone & 1,370 & 0.30 \\
Titanium alloy & 110,000 & 0.33 \\
Co-Cralloy & 218,000 & 0.30 \\
TI6AL4V-ELI & 105,000 & 0.36 \\
Feldspatic ceramic & 70,000 & 0.19 \\
\hline
\end{tabular}




\section{Boundary conditions and loading}

The models were fixed on the mesial and distal exterior surface of the bone segment in $x, y$, and $z$ directions and loaded in two stages. The first stage consisted of simulating the preload on the abutment or prosthetic screws by using the bolt pretension function available in ANSYS Workbench. A preload force of $32 \mathrm{~N} \mathrm{~cm}$ was simulated on the UCLA fixation screw, and a 20 and $10 \mathrm{~N} \mathrm{~cm}$ preload force was simulated on the conical abutment screw and its prosthetic screw, respectively, according to the manufacturer recommendations. In the second stage, a $100 \mathrm{~N}$ occlusal load, applied axially or at 45 degrees obliquely to the implant long axis in the buccolingual direction, was equally distributed over the eight loading areas created previously on the occlusal surface of prosthetic crown models (Figure 2). ${ }^{15}$

\section{Statistical analyses}

Results from 16 models were analyzed separately for immediately and delayed loaded implants via general linear model analysis of variance (ANOVA) in the SAS software package (version 9.2; SAS Institute Inc., Rockville, USA) at a 95\%CI. For each situation of implant loading, the type of prosthetic abutment, implant connection, and occlusal loading were used as variables in the analysis, and the peak maximum principal stress and strain (expressed as the mean \pm standard deviation [SD]) in cortical and trabecular bone were considered as outcome variables. This statistical analysis allowed the calculation of the

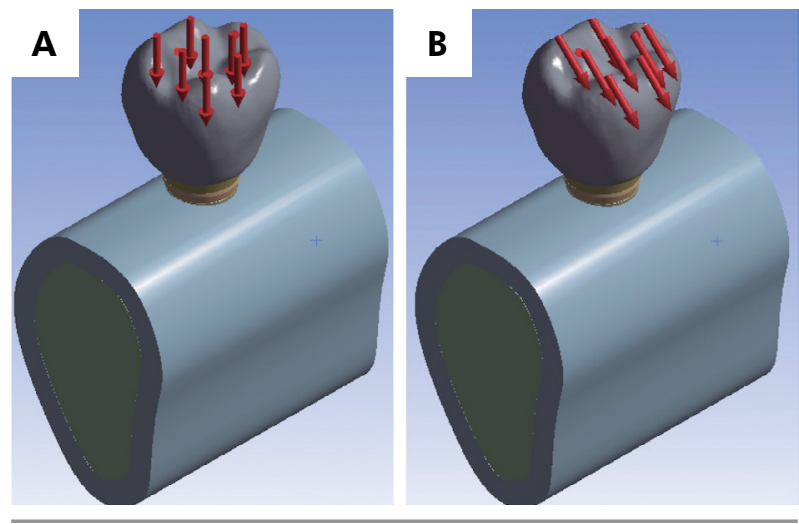

Figure 2. Application of equally distributed $100 \mathrm{~N}$ occlusal load axially $(A)$ and at 45 degrees obliquely (B) to the implant long axis in the buccolingual direction. percentage contribution (percent total sum of squares [\%TSS]) of each variable and of their interactions on the assessed results. ${ }^{19}$ Differences were considered significant at $\mathrm{p}<0.05$.

\section{Results}

The values of peak maximum principal bone stress and strain for immediately or delayed loaded implants are shown in Table 2. The results of ANOVA and the relative contribution of each variable and their interactions on the values of bone stress and strain are shown in Table 3. The patterns of stress and strain distribution in bone tissue were similar between the loading models, with greater concentrations of these forces at the bone region adjacent to the implant first thread and higher magnitudes for immediately loaded implants (Figures 3 and 4).

For the immediately loaded implants, the stress and strain in cortical bone were influenced by the implant-abutment connection type that contributed to $99.82 \%$ of stress $(p=0.007)$ and $95.55 \%$ of strain $(p=0.011)$, with higher values for EH connections (Table 2, 3 and Figure 3). In trabecular bone, the interaction between the type of implant connection and prosthetic abutment was responsible for the most of the stress $(p=0.025)$ and strain $(p=0.009)$ contributed by the interacting variables (Table 3 ). Lower values of bone stress and strain were found when conical abutments were used (Table 2), and the attachment of this abutment to IH implants exhibited best biomechanical behavior, with evenly distributed stress on the bone (Figure 3).

For delayed loaded implants, the type of prosthetic abutment and implant connection had no effect on bone biomechanical behavior. In this situation, the type of occlusal loading (Table 3) contributed to $81.40 \%$ of stress and $70.63 \%$ of strain in cortical bone and to $91.93 \%$ of stress and $89.71 \%$ of strain in trabecular bone, affecting significantly the latter. Oblique loading exhibited the highest bone stress/strain values (Table 2 and Figure 4).

\section{Discussion}

An optimized occlusal load transfer through prosthetic and implant components to the bone-implant interface is a key factor in implant 
Table 2. Peak maximum principal stress and strain in cortical and trabecular bone.

\begin{tabular}{|c|c|c|c|c|c|c|}
\hline \multirow{3}{*}{ Implant Loading } & \multirow{3}{*}{\multicolumn{2}{|c|}{ Variables in study }} & \multicolumn{4}{|c|}{ Mean of stress \pm Standard Deviation } \\
\hline & & & \multicolumn{2}{|c|}{ Stress (MPa) } & \multicolumn{2}{|c|}{ Microstrain $(\mu \varepsilon)$} \\
\hline & & & Cortical Bone & Trabecular Bone & Cortical Bone & Trabecular Bone \\
\hline \multirow{6}{*}{ Immediate loading } & \multirow{2}{*}{ Prosthetic abutment } & UCLA & $222.55( \pm 112.40)$ & $122.92( \pm 27.51)$ & $19.03( \pm 2.07)$ & $108.89( \pm 97.51)$ \\
\hline & & Conical & $215.67( \pm 111.58)$ & $82.83( \pm 71.02)$ & $18.63( \pm 1.90)$ & $54.51( \pm 37.93)$ \\
\hline & \multirow{2}{*}{ Implant connection } & $\mathrm{EH}$ & $316.07( \pm 4.51)$ & $145.52( \pm 1.44)$ & $20.53( \pm 0.43)$ & $88.29( \pm 1.11)$ \\
\hline & & $\mathrm{IH}$ & $122.15( \pm 5.31)$ & $60.22( \pm 44.95)$ & $17.14( \pm 0.42)$ & $75.11( \pm 61.71)$ \\
\hline & \multirow{2}{*}{ Occlusal loading } & Axial & $220.26( \pm 109.79)$ & $102.62( \pm 7.91)$ & $19.12( \pm 1.92)$ & $82.01( \pm 43.65)$ \\
\hline & & Oblique & $217.96( \pm 114.28)$ & $103.13( \pm 59.32)$ & $18.54( \pm 2.02)$ & $81.39( \pm 44.94)$ \\
\hline \multirow{6}{*}{ Delayed loading } & \multirow{2}{*}{ Prosthetic abutment } & UCLA & $13.90( \pm 6.97)$ & $2.04( \pm 0.85)$ & $0.96( \pm 0.44)$ & $1.56( \pm 0.62)$ \\
\hline & & Conical & $12.67( \pm 6.51)$ & $1.96( \pm 0.85)$ & $0.88( \pm 0.45)$ & $1.55( \pm 0.64)$ \\
\hline & \multirow{2}{*}{ Implant connection } & $\mathrm{EH}$ & $11.00( \pm 6.22)$ & $1.97( \pm 0.60)$ & $0.72( \pm 0.42)$ & $1.54( \pm 0.40)$ \\
\hline & & $\mathrm{IH}$ & $15.57( \pm 6.27)$ & $2.04( \pm 1.04)$ & $1.12( \pm 0.35)$ & $1.56( \pm 0.80)$ \\
\hline & \multirow{2}{*}{ Occlusal loading } & Axial & $8.05( \pm 2.45)$ & $1.30( \pm 0.19)$ & $0.59( \pm 0.25)$ & $1.04( \pm 0.19)$ \\
\hline & & Oblique & $18.53( \pm 3.56)$ & $2.71( \pm 0.30)$ & $1.24( \pm 0.25)$ & $2.07( \pm 0.22)$ \\
\hline
\end{tabular}

prognosis, especially in implants subjected to a higher biomechanical risk (i.e., single molar implants). Hence, in this study, 3D nonlinear FEA was carried out to evaluate the influence of the prosthetic abutment type, implant connection, and occlusal loading on bone biomechanical behavior of immediately or delayed loaded single molar implants. The association of this method with statistical factorial analysis allows us to evaluate individually the influence of the cited variables on peri-implant bone stress and strain, which is difficult to investigate using only clinical or in vitro approaches. ${ }^{19,20}$

Table 3. ANOVA results for peak maximum stress and strain in cortical and trabecular bone.

\begin{tabular}{|c|c|c|c|c|c|c|c|c|c|}
\hline \multirow{3}{*}{$\begin{array}{l}\text { Implant } \\
\text { Loading }\end{array}$} & \multirow{3}{*}{ Variables in study } & \multicolumn{4}{|c|}{ Stress } & \multicolumn{4}{|c|}{ Strain } \\
\hline & & \multicolumn{2}{|c|}{ Cortical Bone } & \multicolumn{2}{|c|}{ Trabecular Bone } & \multicolumn{2}{|c|}{ Cortical Bone } & \multicolumn{2}{|c|}{ Trabecular Bone } \\
\hline & & p & $\%$ TSS & $p$ & $\%$ TSS & $p$ & $\%$ TSS & $p$ & \%TSS \\
\hline \multirow{7}{*}{$\begin{array}{l}\text { Immediate } \\
\text { loading }\end{array}$} & Prosthetic abutment & 0.181 & $0.13 \%$ & $0.024^{*}$ & $15.60 \%$ & 0.095 & $1.34 \%$ & $0.009^{*}$ & $50.24 \%$ \\
\hline & Implant-abutment connection & $0.007^{*}$ & $99.82 \%$ & $0.011^{*}$ & $70.59 \%$ & $0.011^{*}$ & $95.55 \%$ & $0.038^{*}$ & $2.95 \%$ \\
\hline & Occlusal loading & 0.458 & $0.01 \%$ & 0.790 & $0 \%$ & 0.065 & $2.82 \%$ & 0.572 & $0.01 \%$ \\
\hline & Prosthetic abutment $\times$ Implant connection & 0.798 & 0 & $0.025^{*}$ & $13.79 \%$ & 0.249 & $0.18 \%$ & $0.009^{*}$ & $46.78 \%$ \\
\hline & Prosthetic abutment $\times$ Occlusal loading & 0.302 & $0 \%$ & 0.525 & $0.02 \%$ & 0.338 & $0.03 \%$ & 0.475 & $0.01 \%$ \\
\hline & Implant connection $\times$ Occlusal loading & 0.773 & $0.04 \%$ & 0.939 & 0 & 0.519 & $0.09 \%$ & 0.570 & $0.01 \%$ \\
\hline & Total & - & $100 \%$ & - & $100 \%$ & - & $100 \%$ & - & $100 \%$ \\
\hline \multirow{7}{*}{$\begin{array}{l}\text { Delayed } \\
\text { loading }\end{array}$} & Prosthetic abutment & 0.604 & $1.14 \%$ & 0.608 & $0.30 \%$ & 0.622 & $1.03 \%$ & 0.829 & $0.01 \%$ \\
\hline & Implant connection & 0.228 & $15.50 \%$ & 0.643 & $0.23 \%$ & 0.181 & $26.37 \%$ & 0.735 & $0.04 \%$ \\
\hline & Occlusal loading & 0.103 & $81.40 \%$ & 0.051 & $91.93 \%$ & 0.112 & $70.63 \%$ & $0.030^{*}$ & $89.71 \%$ \\
\hline & Prosthetic abutment $\times$ Implant connection & 0.603 & $1.16 \%$ & 0.542 & $0.45 \%$ & 0.577 & $1.38 \%$ & 0.656 & $0.07 \%$ \\
\hline & Prosthetic abutment $\times$ Occlusal loading & 0.653 & $0.80 \%$ & 0.779 & $0.08 \%$ & 0.786 & $0.28 \%$ & 0.920 & $0 \%$ \\
\hline & Implant connection $\times$ Occlusal loading & 0.868 & 0 & 0.180 & $7.02 \%$ & 0.771 & $0.32 \%$ & 0.088 & $10.17 \%$ \\
\hline & Total & - & $100 \%$ & - & $100 \%$ & - & $100 \%$ & - & $100 \%$ \\
\hline
\end{tabular}

$* p<0.05 . \%$ TSS: percent total sum of squares. 
A



$<133 \mathrm{MPa} \quad 133-40 \mathrm{MPa}$ 40-20 MPa 20-0 MPa >0 MPa
B
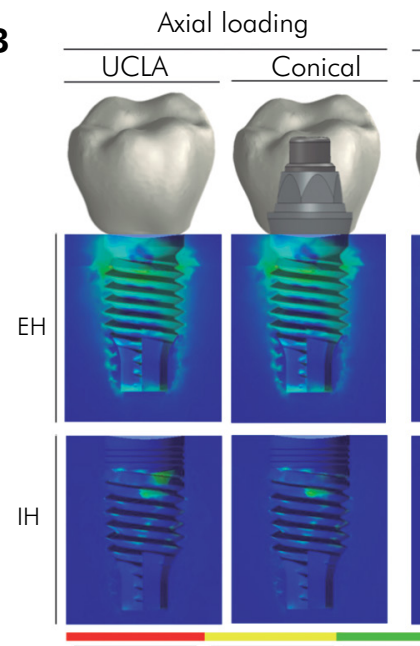

$<100 \mu \varepsilon \quad 100-50 \mu \varepsilon \quad 50-5 \mu \varepsilon$
Oblique loading
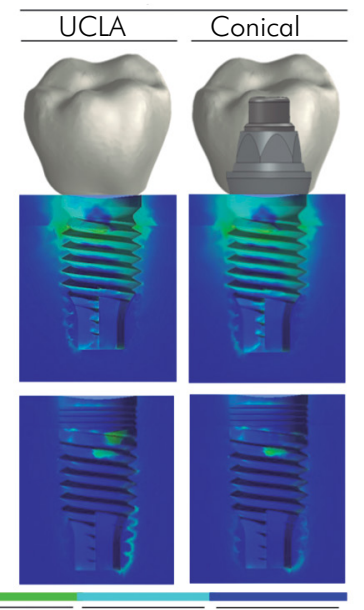

$>0 \mu \varepsilon$

Figure 3. Stress (A) and strain (B) distribution in peri-implant bone of immediately loaded implants.

Immediately loaded implants exhibited higher values of bone stress and strain than delayed loaded implants, regardless of the variables evaluated. Implants subjected to immediate loading are in frictional contact with bone, which is responsible for their primary stability. Frictional contact was simulated in this study by using a frictional contact coefficient $(\mu=0.3)$ at the bone-implant interface. This form of contact transfers pressure, tangential, and frictional forces, ${ }^{18}$ which most likely explain the highest peri-implant bone stress/strain values for

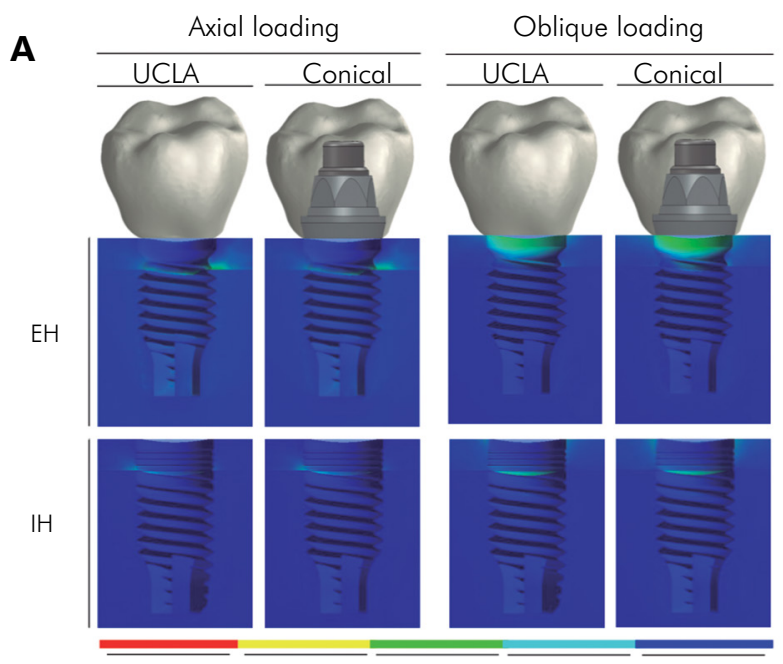

$<133 \mathrm{MPa} 133-40 \mathrm{MPa}$ 40-20 MPa 20-0 MPa >0 MPa immediately loaded implants observed in this and previous studies. ${ }^{16,21}$ In delayed loading, the implants are considered osseointegrated, and this situation was simulated in this study by using a "bonded" contact at bone-implant interface. ${ }^{18}$ An even load distribution has been observed in peri-implant bone around osseointegrated implants. ${ }^{16}$ Thus, the type of bone-implant interface has a strong influence on stress/strain in peri-implant bone. Clinical studies comparing immediately or delayed loaded implants in the posterior region have shown slightly lower

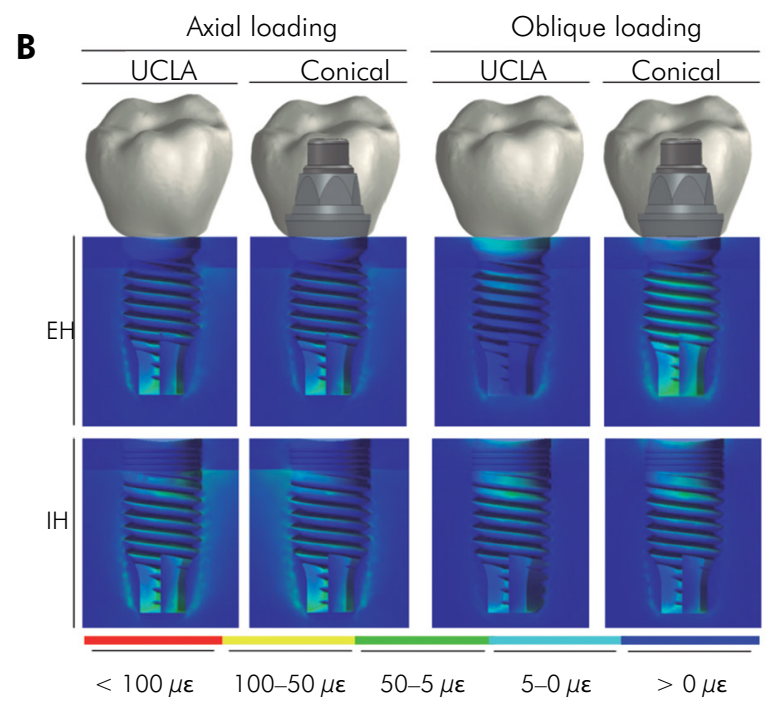

Figure 4. Stress (A) and strain (B) distribution in peri-implant bone of delayed loaded implants. 
survival rates for immediately loaded implants. ${ }^{22,23}$ Furthermore, Schincaglia et al. ${ }^{23}$ have observed that the radiographic bone level for immediately loaded implants is significantly lower than that reported for delayed loaded implants. However, long-term studies are needed to confirm these results.

As a consequence of efficient load transfer in osseointegrated implants, the type of abutment and implant connection played a minor role in distribution and magnitude of bone stress/strain. It is noteworthy that the type of occlusal loading was responsible for the most of bone stress/strain generated in this situation, with highest values for oblique loading, because loading in the nonaxial direction increases the bending moments, causing stress gradients along the implant surface. ${ }^{24}$ Clinically, the harmful effects of bending moments on single tooth implants can be minimized by narrowing the buccolingual and mesiodistal dimensions of the restorations and avoiding premature contacts through a careful occlusal analysis. ${ }^{25}$

Unlike delayed loaded implants with a bonded bone-implant interface, immediately loaded implants exhibit only frictional contacts with bone at the beginning of the osseointegration process. In this context, the search for more stable implant connections and abutments that can decrease occlusal stress and improve the load distribution in bone is essential for osseointegration success. In the immediate loading situation, we observed a greater influence of abutment type and implant connection on bone stress and strain, compared to that for the delayed loading situation. Among the types of implant connections that were evaluated in this study, implants with EH connections produced higher bone stress/strain than that produced by implants with IH connections, because the reduced size of the $\mathrm{EH}$ is insufficient to provide stability to this connection under functional loading. In contrast, implants with internal connections exhibit greater stability of their prosthetic connections due to the higher contact area at the abutment-implant interface, ${ }^{13}$ resulting in lower stress/strain forces on bone than those generated by EH systems. At the present time, however, the paucity of studies on the impact of the implant-abutment connection on crestal bone level changes is insufficient to warrant the drawing of any conclusions. ${ }^{26,27}$ Hence, future randomized controlled clinical trials are needed to assess the effect of different implant-abutment connections on peri-implant bone level.

In addition to implant connection, the abutment type significantly affected the magnitude and distribution of bone stress and strain in immediately loaded implants. In general, conical abutments induced lower stress/strain in bone than that induced by UCLA abutments. The improved biomechanical behavior of conical abutments can be attributed to the presence of two screwed connections in this abutment, which increase the total area for stress/strain distribution and dissipation in peri-implant bone. However, the mechanical behavior of prosthetic abutments was dependent on the type of implant connection to which they were attached. The influence of abutment type apparently became stronger when the IH implant connection was used, because this connection type provides greater stability to the abutment. ${ }^{13}$

It should be noted that there are inherent limitations to in silico simulation of clinical scenarios, primarily due to assumptions concerning forces, material properties, and boundary and loading conditions. Bone is a complex dynamic structure, and its characteristics might substantially vary among individuals. In this study, bone tissue was considered as homogeneous and isotropic as a result of numerical convergence considerations for nonlinear analysis. Similar bone mechanical properties were postulated in other studies that showed comparable results. ${ }^{28}$ Other factors, such as static occlusal loading, that were applied to the models could play a more prominent role in bone response, and the simulation of dynamic loading, representing the chewing movements, needs to be considered in future studies. It is important to emphasize that, in spite of FEA limitations, additional measures were taken in this study, such as the creation of accurate analytical models based on tomographic images, the simulation of preload in prosthetic screws, and the use of frictional contact elements between implant-abutment components. We included these factors because they have been 
neglected in previous studies ${ }^{7,21}$ and might affect load transmission to bone and, consequently, the obtained results.

\section{Conclusions}

Within the limitations of this study, it can be concluded that the type of prosthetic abutment influences bone stress and strain in immediately loaded implants. The conical abutment associated

\section{References}

1. Wennerberg A, Albrektsson T. Current challenges in successful rehabilitation with oral implants. J Oral Rehabil. 2011;38(4):286-94. doi:10.1111/j.1365-2842.2010.02170.x

2. Bornstein MM, Halbritter S, Harnisch H, Weber HP, Buser D. A retrospective analysis of patients referred for implant placement to a specialty clinic: indications, surgical procedures, and early failures. Int J Oral Maxillofac Implants. 2008;23(6):1109-16.

3. Weber HP, Sukotjo C. Does the type of implant prosthesis affect outcomes in the partially edentulous patient? Int J Oral Maxillofac Implants. 2007;22 Suppl:140-72. Erratum in Int J Oral Maxillofac Implants. 2008;23(1):56.

4. Shigemitsu R, Ogawa T, Matsumoto T, Yoda N, Gunji Y, Yamakawa $Y$, et al. Stress distribution in the peri-implant bone with splinted and non-splinted implants by in vivo loading data-based finite element analysis. Odontology. 2013;101(2):222-6. doi:10.1007/s10266-012-0077-y

5. Isidor F. Influence of forces on peri-implant bone. Clin Oral Implants Res. 2006;17(Suppl 2):8-18. doi:10.1111/j.1600-0501.2006.01360.x

6. Qian J, Wennerberg A, Albrektsson T. Reasons for marginal bone loss around oral implants. Clin Implant Dent Relat Res. 2012;14(6):792-807. doi:10.1111/cid.12014

7. Pessoa RS, Muraru L, Marcantonio Júnior E, Vaz LG, Sloten JV, Duyck, J et al. Influence of implant connection type on the biomechanical environment of immediately placed implants - CT-based nonlinear, three-dimensional finite element analysis. Clin Implant Dent Relat Res. 2010;12(3):219-34. doi: 10.1111/j.1708-8208.2009.00155.x

8. Eraslan O, Inan O. The effect of thread design on stress distribution in a solid screw implant: a 3D finite element analysis. Clin Oral Investig. 2010;14(4):411-6. doi:10.1007/s00784-009-0305-1

9. Baggi L, Cappelloni I, Di Girolamo M, Maceri F, Vairo G. The influence of implant diameter and length on stress distribution of osseointegrated implants related to crestal bone geometry: a three-dimensional finite element analysis. J Prosthet Dent. 2008;100(6):422-31. doi:10.1016/S0022-3913(08)60259-0 to IH implant connection optimizes the distribution and dissipation of load forces in peri-implant bone.

\section{Acknowledgements}

This study was supported by Fundação de Amparo à Pesquisa do Estado de São Paulo (FAPESP no. 2011/14001-3). The authors give special thanks to Dr. Carlos Murgel (Campinas, Brazil) for providing the tomographic images.

10. Tian K, Chen J, Han L, Yang J, Huang W, Wu D. Angled abutments result in increased or decreased stress on surrounding bone of single-unit dental implants: a finite element analysis. Med Eng Phys. 2012;34(10):1526-31. doi:10.1016/j.medeng phy.2012.10.003

11. Tonella BP, Pellizzer EP, Ferraço R, Falcón-Antenucci RM, Carvalho PS, Goiato MC. Photoelastic analysis of cemented or screwed implant-supported prostheses with different prosthetic connections. J Oral Implantol. 2011;37(4):401-10. doi:10.1563/AAID-JOI-D-10-00044

12. Ochiai KT, Ozawa S, Caputo AA, Nishimura RD. Photoelastic stress analysis of implant-tooth connected prostheses with segmented and nonsegmented abutments. J Prosthet Dent. 2003;89(5):495-502. doi:10.1016/S0022-3913(03)00167-7

13. Maeda Y, Satoh T, Sogo M. In vitro differences of stress concentrations for internal and external hex implant-abutment connections: a short communication. J Oral Rehabil. 2006;33(1):75-8. doi:10.1111/j.1365-2842.2006.01545.x

14. Lekholm, U, Zarb G. Patient selection and preparation. In: Brånemark, P-I, Zarb, GA, Albrektsson, T, editors. Tissue integrated prostheses: osseointegration in clinical dentistry. Chicago: Quintessence Publishing Company; 1985. p. 199-209.

15. Hattori $Y$, Satoh C, Kunieda T, Endoh R, Hisamatsu H, Watanabe $\mathrm{M}$. Bite forces and their resultants during forceful intercuspal clenching in humans. J Biomech 2009 Jul;42(10):1533-8. doi:10.1016/j.jbiomech.2009.03.040

16. Huang HL, Hsu JT, Fuh LJ, Tu MG, Ko CC, Shen YW. Bone stress and interfacial sliding analysis of implant designs on an immediately loaded maxillary implant: a non-linear finite element study. J Dent. 2008;36(6):409-17. doi:10.1016/j.jdent.2008.02.015

17. Chu CM, Huang HL, Hsu JT, Fuh LJ. Influences of internal tapered abutment designs on bone stresses around a dental implant: three-dimensional finite element method with statistical evaluation. J Periodontol. 2012;83(1):111-8. doi:10.1902/jop.2011.110087

18. Murakami N, Wakabayashi N. Finite element contact analysis as a critical technique in dental biomechanics: a review. J Prosthodont Res. 2014;58(2):92-101. doi:10.1016/j.jpor.2014.03.001 
19. Dar FH, Meakin JR, Aspden RM. Statistical methods in finite element analysis. J Biomech. 2002;35(9):1155-61. doi:10.1016/S0021-9290(02)00085-4

20. Geng JP, Tan KB, Liu GR. Application of finite element analysis in implant dentistry: a review of the literature. J Prosthet Dent. 2001;85(6):585-98. doi:10.1067/mpr.2001.115251

21. Pessoa RS, Bezerra FJ, Sousa RM, Sloten JV, Casati MZ, Jaecques SV. Biomechanical evaluation of platform switching: different mismatch sizes, connection types, and implant protocols. J Periodontol. 2014;85(9):1161-71. doi:10.1902/jop.2014.130633

22. Güncü MB, Aslan Y, Tümer C, Güncü GN, Uysal S. In-patient comparison of immediate and conventional loaded implants in mandibular molar sites within 12 months. Clin Oral Implants Res. 2008;19(4):335-41. doi:10.1111/j.1600-0501.2007.01471.x

23. Schincaglia GP, Marzola R, Giovanni GF, Chiara CS, Scotti R. Replacement of mandibular molars with single-unit restorations supported by wide-body implants: immediate versus delayed loading. A randomized controlled study. Int J Oral Maxillofac Implants. 2008;23(3):474-80.
24. Watanabe F, Hata Y, Komatsu S, Ramos TC, Fukuda $\mathrm{H}$. Finite element analysis of the influence of implant inclination, loading position, and load direction on stress distribution. Odontology. 2003;91(1):31-6. doi:10.1007/s10266-003-0029-7

25. Meyer G, Fanghänel J, Proff P. Morphofunctional aspects of dental implants. Ann Anat. 2012;194(2):190-4. doi:10.1016/j.aanat.2011.09.006

26. Schwarz F, Hegewald A, Becker J. Impact of implant-abutment connection and positioning of the machined collar/microgap on crestal bone level changes: a systematic review. Clin Oral Implants Res. 2014;25(4):417-25. doi:10.1111/clr.12215

27. Lin MI, Shen YW, Huang HL, Hsu JT, Fuh LJ. A retrospective study of implant-abutment connections on crestal bone level. J Dent Res. 2013;92(12 Suppl):202S-7S. doi:10.1177/0022034513510322

28. Lin CL, Lin YH, Chang SH. Multi-factorial analysis of variables influencing the bone loss of an implant placed in the maxilla: prediction using FEA and SED bone remodeling algorithm. J Biomech. 2010;43(4):644-51. doi:10.1016/j.jbiomech.2009.10.030 